\title{
PENERAPAN STRATEGI EXAMPLE NON EXAMPLE DENGAN BANTUAN MEDIA GAMBAR PADA MATERI PERISTIWA ALAM UNTUK MENINGKATAN HASIL BELAJAR SISWA KELAS V SEMESTER II SDN 4 PATOKAN TAHUN PELAJARAN 2018/2019
}

\author{
Dodik Eko Yulianto ${ }^{1}$, \\ Program Studi Pendidikan Guru Sekolah Dasar, Fakultas Keguruan Dan Ilmu Pendidikan, \\ Universitas Abdurachman Saleh Situbondo \\ Jl. PB Sudirman No. 7 \\ Email: ekoyuliantododik@gmail,com
}

\begin{abstract}
Abstrak: Materi pelajaran yang disampaikan guru kepada siswa seharusnya senantiasa diingat agar siswa nantinya siap menghadapi ujian kenaikan kelas yang mau tidak mau akan mereka hadapi. Seorang guru harus mencari cara atau strategi untuk membangkitkan ingatan siswa terhadap segala materi yang sudah pernah diterimanya dalam proses pembelajaran. Pembelajaran adalah proses yang dapat mempengaruhi perubahan dari segi perilaku dan cara berfikir pada diri manusia yang dapat ditingkatkan. Strategi yang digunakan dalam penelitian ini adalah strategi Example Non Example. Example Non Example adalah strategi yang dapat digunakan untuk mengajarkan definisi konsep. Penelitian ini menggunakan Penelitian Tindakan Kelas sebanyak 2 siklus. Sasaran penelitian adalah siswa kelas V semester II di SD Negeri 4 Patokan Situbondo. Data yang diperoleh berupa hasil Tugas kelompok, tes formatif, lembar observasi kegiatan belajar mengajar. Hasil analisis menunjukkan bahwa siswa mengalami peningkatan hasil belajar dari siklus I menuju siklus II, yaitu masing-masing 71,43\% dan 100\%. Kesimpulan dari penelitian ini adalah strategi Example Non Example dengan bantuan media gambar dapat berpengaruh positif terhadap hasil belajar siswa mata pelajaran IPA materi peristiwa alam kelas V semester II di SD Negeri 4 Patokan Situbondo.
\end{abstract}

Kata Kunci: Example Non Example, Hasil belajar. 


\section{PENDAHULUAN}

Sekolah adalah sebuah lembaga yang dirancang untuk mengajarkan siswa/murid di bawah pengawasan guru. Belajar di sekolah dapat mengembangkan cara berfikir, bersikap, dan mengembangkan keterampilan yang dimiliki peserta didik, hal tersebut dilakukan ketika peserta didik mengikuti program pembelajaran. Pembelajaran dapat dikatakan sebagai hasil dari daya ingat peserta didik dalam aspek kognitif, afektif, dan psikomotorik yang berpengaruh pada pemahaman. Pembelajaran merupakan suatu sistem, yang terdiri atas berbagai komponen yang saling berhubungan satu dengan yang lain (Rusman, 2012: 1).

Gagne (dalam Huda, 2013: 3) menyatakan bahwa "pembelajaran diartikan sebagai proses modifikasi dalam kapasitas manusia yang bisa dipertahankan dan ditingkatkan levelnya." Suatu proses belajar dapat dikatakan berhasil apabila peserta didik telah menempuh ujian akhir dan peserta didik berhasil mencapai target nilai yang telah ditentukan. Peserta didik akan menempuh ujian semester ganjil dan ujian kenaikan kelas bagi siswa kelas lima sekolah dasar. Menghadapi tes atau ujian kenaikan kelas, peserta didik sekolah dasar perlu mendapatkan pengembangan terhadap proses belajar mereka. Proses belajar mengajar harus dilakukan secara bertahap, dan membuat siswa nyaman dalam proses pembelajaran. Setiap mata pelajaran memiliki kriteria ketuntasan minimum dalam memahami materi, untuk mata pelajaran IPA, kriteria ketuntasan minimum pada angka 65. Nilai siswa kelas V di SD Negeri 4 Patokan Situbondo untuk mata pelajaran IPA secara klasikal masih berada di bawah angka 85\%, maka dari itu perlu adanya pengembangan dalam proses belajar mengajar.

Guru adalah pendidik dan pengajar pada pendidikan anak usia dini jalur sekolah atau pendidikan formal, pendidikan dasar dan menengah. Sebagai seorang guru, harus berfikir bagaimana cara agar peserta didik tidak mudah melupakan materi yang telah disampaikan dan mereka siap dalam menghadapi ujian kenaikan kelas. Guru berfikir bagaimana membuat suatu proses belajar mengajar menjadi tidak mudah dilupakan oleh peserta didik. Guru harus mencari strategi agar peserta didik mampu untuk mengingat materi yang pernah mereka terima.Peserta didik adalah anggota masyarakat yang berusaha mengembangkan potensi diri melalui proses pembelajaran pada jalur pendidikan baik pendidikan formal maupun pendidikan non formal, pada jenjang pendidikan dan jenis pendidikan tertentu. Salah satu strategi pembelajaran yang bisa membuat siswa bisa dan mengingat kembali materi pelajaran yang telah diterima adalah dengan menerapkan 
Strategi Example Non Example dengan bantuan media gambar pada mata pelajaran ilmu pengetahuan alam materi peristiwa alam. Pengajaran akan lebih efektif apabila objek dan kejadian yang menjadi bahan pengajaran dapat divisualisasikan secara realistik menyerupai keadaan sebenarnya, namun tidaklah berarti bahwa media harus selalu menyerupai keadaan yang sebenarnya (Sudjana dan Rivai, 2010: 9).

\section{Tabel Hasil Belajar Siswa Prasiklus}

\begin{tabular}{|c|c|c|c|c|}
\hline \multirow[t]{2}{*}{ No. } & \multirow[t]{2}{*}{ Nama Siswa } & \multirow[t]{2}{*}{ Nilai/Skor } & \multicolumn{2}{|c|}{ Keterangan } \\
\hline & & & Tuntas & Tidak Tuntas \\
\hline 1. & Ahmadi & 70 & $\sqrt{ }$ & \\
\hline 2. & Fera Dwi Yanti & 70 & $\sqrt{ }$ & \\
\hline 3. & Hendy Febriansa & 70 & $\sqrt{ }$ & \\
\hline 4. & Lilis Karlina & 50 & & $\sqrt{ }$ \\
\hline 5. & Rustini & 50 & & $\sqrt{ }$ \\
\hline 6. & Sania Nur Cahya & 70 & $\sqrt{ }$ & \\
\hline 7. & Wedy Ardiansyah & 50 & & $\sqrt{ }$ \\
\hline & Jumlah Skor & 430 & 4 & 3 \\
\hline & Klasikal & & $57,14 \%$ & $42,86 \%$ \\
\hline
\end{tabular}

Jumlah skor

$$
=430
$$

Jumlah skor maksimal $=700$

Skor Tercapai $/$ Rata-rata $=\frac{\text { Jumlah Skor }}{\text { Skor Maksimal }} \mathrm{x}$ 100

$$
\frac{430}{700} \times 100
$$$$
=61,5
$$

Siswa Tuntas

$$
=4 \text { Siswa }
$$

Siswa Tidak Tuntas $=3$ Siswa

Ketuntasan Belajar Klasikal= $\frac{\text { Siswa Tuntas }}{\Sigma \text { Siswa }} \times 100$

$=\frac{4}{7} \times 100 \%$ Ketuntasan Klasikal

$=57,14 \%$ (Belum Tuntas)
Tabel Distribusi Hasil Belajar Siswa Prasiklus

\begin{tabular}{|c|l|c|}
\hline No. & \multicolumn{1}{|c|}{ Aspek yang diamati } & Presentase \\
\hline 1. & Nilai rata-rata & $\mathbf{6 1 , 5}$ \\
\hline 2. & Jumlah siswa yang tuntas belajar & $\mathbf{4}$ \\
\hline 3. & Presentase ketuntasan belajar klasikal & $\mathbf{5 7 , 1 4} \%$ \\
\hline
\end{tabular}

Hasil observasi prasiklus menunjukkan bahwa nilai siswa masih rendah baik secara mandiri maupun secara klasikal yang masih belum dapat dikatakan tuntas.Maka dari itu dilaksanakannya penelitian ini bertujuan untuk meningkatkan hasil belajar siswa dengan menerapkan strategi Example Non Example dengan bantuan media gambar pada mata pelajaran IPA materi Peristiwa Alam untuk siswa kelas V semester II di SD Negeri 4 Patokan Situbondo tahun pelajaran 2018/2019.

\section{METODE PENELITIAN}

Jenis penelitian adalah Penelitian Tindakan Kelas dengan prosedur penelitian sebagai berikut: identifikasi masalah $\rightarrow$ perencanaan $\rightarrow$ tindakan $\rightarrow$ observasi $\rightarrow$ refleksi $\rightarrow$ perencanaan ulang untuk siklus berikutnya. Penelitian pada dasarnya merupakan cara ilmiah untuk mendapatkan data dengan tujuan kegunaan tertentu (Sugiyono, 2012: 2). Penelitian mempunyai tujuan yaitu memperbaiki dan meningkatkan kualitas pembelajaran serta membantu memberdayakan guru dalam memecahkan masalah pembelajaran di sekolah.

Penelitian tindakan kelas ini, mahasiswa berperan sebagai peneliti. Guru 
dan peneliti bekerjasama dan menjadi penanggung jawab penuh penelitian. Tujuan utama dari penelitian tindakan kelas ini adalah meningkatkan hasil belajar siswa, dan membantu guru untuk memecahkan permasalahan yang ada di kelas. Tempat penelitian adalah tempat yang digunakan dalam melakukan penelitian tindakan kelas untuk memperoleh data yang diinginkan. Penelitian ini bertempat di SD Negeri 4 Patokan Situbondo Kecamatan Situbondo Kabupaten Situbondo. Waktu penelitian adalah waktu berlangsungnya penelitian tindakan kelas. Penelitian ini dilaksanakan pada bulan maret di semester genap tahun pelajaran 2018/2019. Subjek penelitian adalah siswa-siswi kelas V semester II di SD Negeri 4 Patokan Situbondo Kecamatan Situbondo Kabupaten Situbondo.

Instrumen yang digunakan dalam penelitian ini terdiri dari:

1. Silabus, yaitu seperangkat rencana dan pengaturan tentang kegiatan pembelajaran pengolahan kelas, serta penilaian hasil belajar.

2. Rencana Pelaksanaan Pembelajaran (RPP), yaitu merupakan perangkat pembelajaran yang digunakan sebagai pedoman guru dalam mengajar dan disusun untuk satu kali pertemuan.

3. Lembar Kegiatan Siswa, yaitu lembar kegiatan yang akan digunakan siswa untuk membantu pengumpulan data hasil analisis siswa.
Data-data yang diperlukan dalam penelitian tindakan kelas ini diperoleh melalui proses observasi dan wawancara bersama guru/wali kelas V di SD Negeri 4 Patokan Situbondo, hasil observasi penerapan strategi Example Non Example dan tes formatif khusus mata pelajaran IPA materi Peristiwa Alam untuk siswa-siswi kelas V di SD Negeri 4 Patokan Situbondo Kecamatan Situbondo, Kabupaten Situbondo. Data dalam penelitian tindakan berfungsi sebagai landasan refleksi. Data mewakili tindakan dalam arti bahwa data itu memungkinkan peneliti memperbaiki tindakan sebelumnya. Data berupa seluruh catatan penting mengenai hasil pengamatan, yang didapat melalui instrumen/alat perolehan data. Data penelitian tindakan kelas dapat berbentuk catatan, foto, dan hasil belajar.

\section{HASIL DAN PEMBAHASAN}

Data hasil penelitian pada siklus I adalah sebagai berikut: 
Tabel Kegiatan Guru Siklus I

\begin{tabular}{|c|l|c|c|c|c|}
\hline No. & \multicolumn{1}{|c|}{ Aspek yang diamati } & \multicolumn{4}{|c|}{ Skala Nilai } \\
\hline & & $\mathbf{l}$ & $\mathbf{2}$ & $\mathbf{3}$ & $\mathbf{4}$ \\
\hline 1. & Menyampaikan pengertian peristiwa alam & & & $\sqrt{ }$ & \\
\hline 2. & Kesiapan alat dan media pembelajaran & & & $\sqrt{ }$ & \\
\hline 3. & Kesesuaian media dengan mater & & & $\sqrt{ }$ & \\
\hline 4. & Membagi siswa dalam kelompok & & & $\sqrt{ }$ & \\
\hline 5. & Menjelaskan prosedur kerja kelompok & & $\sqrt{ }$ & & \\
\hline 6. & Mendampingi tim dalam bekerjasama & & & $\sqrt{ }$ & \\
\hline 7. & Menggunakan media secara efektif & & & $\sqrt{ }$ & \\
\hline 8. & $\begin{array}{l}\text { Menunjukkan penguasaan dalam } \\
\text { menggunakan media pembelajaran }\end{array}$ & & $\sqrt{ }$ & & \\
\hline 9. & $\begin{array}{l}\text { Melibatkan siswa dalam pemanfaatan } \\
\text { media }\end{array}$ & & & $\sqrt{ }$ & \\
\hline 10. & $\begin{array}{l}\text { Mengaitkan media dengan realitas } \\
\text { kehidupan }\end{array}$ & & $\sqrt{ }$ & & \\
\hline 11. & $\begin{array}{l}\text { Memberi kesempatan kepada tim untuk } \\
\text { membacakan hasil diskusi }\end{array}$ & & & $\sqrt{ }$ & \\
\hline 12. & Menjelaskan materi secara menyeluruh & & & $\sqrt{ }$ & \\
\hline 13. & Memberi evaluasi & & & $\sqrt{ }$ & \\
\hline & \multicolumn{1}{|c|}{ Total } & & $\mathbf{3 6}$ & \\
\hline
\end{tabular}

Skor $=\frac{\text { Skor Total }}{\text { Skor Maksimal }} \times 100$

Keterangan :

$$
\begin{aligned}
& =\frac{36}{52} \times 100 \\
& =69,2
\end{aligned}
$$

1 = Tidak Baik

$2=$ Kurang Baik

3 = Cukup baik

4 = Baik

\section{Standar Ketuntasan Minimal 65}

(Sumber: Kurikulum 2013)

\section{Tabel Kegiatan Siswa siklus I}

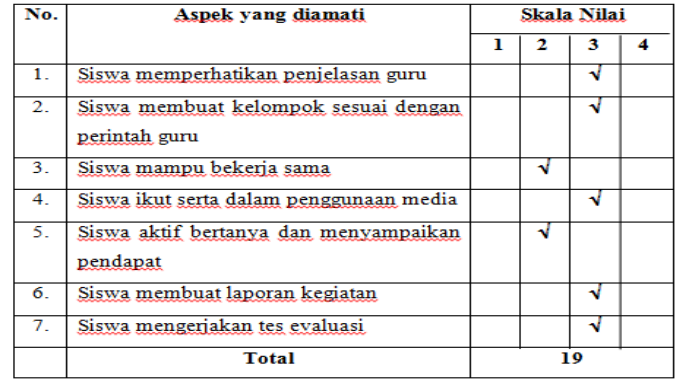

Skor $=\frac{\text { Skor Total }}{\text { Skor Maksimal }} \times 100$

Keterangan :

$$
=\frac{19}{28} \times 100
$$

$$
=67,9
$$

1 = Tidak Baik

$2=$ Kurang Baik

$3=$ Cukup baik

$4=$ Baik

\section{Standar Ketuntasan Minimal 65}

(Sumber: Kurikulum 2013)

Tabel Hasil Belajar Siswa Siklus I

\begin{tabular}{|c|l|c|c|c|}
\hline No. & \multicolumn{1}{|c|}{ Nama Siswa } & Nilai/Skor & \multicolumn{2}{|c|}{ Keterangan } \\
\cline { 4 - 5 } & & & Tuntas & Tidak Tuntas \\
\hline 1. & Ahmadi & 80 & $\sqrt{ }$ & \\
\hline 2. & Fera Dwi Yanti & 70 & $\sqrt{ }$ & \\
\hline 3. & Hendy Febriansa & 70 & $\sqrt{ }$ & \\
\hline 4. & Lilis Karlina & 60 & & $\sqrt{ }$ \\
\hline 5. & Rustini & 60 & & $\sqrt{ }$ \\
\hline 6. & Sania Nur Cahya & 80 & $\sqrt{ }$ & \\
\hline 7. & Wedy Ardiansyah & 80 & $\sqrt{ }$ \\
\hline
\end{tabular}

Skor maksimal $=700$

Skor Tercapai/Rata-rata

$=\frac{\text { Jumlah Skor }}{\text { Skor Maksimal }} \times 100$

$=\frac{500}{700} \times 100$

$=71,43$

Ketuntasan Belajar Klasikal= $\frac{\text { Siswa Tuntas }}{\Sigma \text { Siswa }} \times 100$

$=\frac{5}{7} \times 100 \%$ Ketuntasan Klasikal

$=71,43 \%($ Belum Tuntas $)$

Tabel Distribusi Hasil Belajar Siswa

Siklus I 


\begin{tabular}{|c|l|c|}
\hline No. & \multicolumn{1}{|c|}{ Aspek yang diamati } & Presentase \\
\hline 1. & Nilai rata-rata & $\mathbf{7 1 , 4 3}$ \\
\hline 2. & Jumlah siswa yang tuntas belajar & $\mathbf{5}$ \\
\hline 3. & Presentase ketuntasan belajar klasikal & $\mathbf{7 1 , 4 3 \%}$ \\
\hline
\end{tabular}

Pada tahap refleksi ini akan dikaji apa yang telah terlaksana dengan baik maupun yang masih kurang baik dalam proses belajar menggunakan strategi Example Non Example dengan bantuan media gambar, data yang diperoleh dapat diuraikan sebagai berikut:

1). Selama proses belajar mengajar, guru dan siswa telah melaksanakan proses pembelajaran dengan cukup baik dengan hasil 69,2 dan 67,9. Angka tersebut di atas angka standar yang ditentukan yaitu 65 .

2). Siswa masih kurang aktif selama proses belajar mengajar.

3). Perlu adanya perbaikan pada siklus berikutnya, agar aspek yang diamati dapat berkembang ke arah baik.

4). Hasil belajar siswa belum mengalamai ketuntasan, dapat dilihat secara klasikal yaitu $71,43 \%$. Nilai tersebut masih jauh di bawah standar yang ditentukan yaitu $85 \%$.

Pada siklus I guru telah menerapkan strategi Example Non Example dengan bantuan media gambar dengan cukup baik, namun dilihat dari aktifitas siswa serta hasil belajar belum dapat dikatakan baik. Diperlukan beberapa revisi atau perbaikan agar aspek yang diamati dapat dikembangkan ke arah lebih baik. Tindakan yang akan dilakukan berikutnya perlu dimaksimalkan lebih dari hasil yang telah dicapai pada siklus I

Data hasil penelitian pada siklus II adalah sebagai berikut:

\section{Tabel Kegiatan Guru Siklus II}

\begin{tabular}{|c|l|c|c|c|c|}
\hline No. & \multicolumn{1}{|c|}{ Aspek yang diamati } & \multicolumn{3}{|c|}{ Skala Nilai } \\
\hline & & $\mathbf{l}$ & $\mathbf{2}$ & $\mathbf{3}$ & $\mathbf{4}$ \\
\hline 1. & Menyampaikan pengertian peristiwa alam & & & $\sqrt{ }$ & \\
\hline 2. & Kesiapan alat dan media pembelajaran & & & $\sqrt{ }$ & \\
\hline 3. & Kesesuaian media dengan materi & & & $\sqrt{ }$ & \\
\hline 4. & Membagi siswa dalam kelompok & & & & $\sqrt{ }$ \\
\hline 5. & Menjelaskan prosedur kerja kelompok & & & & $\sqrt{ }$ \\
\hline 6. & Mendampingi tim dalam bekerjasama & & & & $\sqrt{ }$ \\
\hline 7. & Menggunakan media secara efektif & & & & $\sqrt{ }$ \\
\hline 8. & $\begin{array}{l}\text { Menunjukkan penguasaan dalam } \\
\text { menggunakan media pembelajaran }\end{array}$ & & & & $\sqrt{ }$ \\
\hline 9. & $\begin{array}{l}\text { Melibatkan siswa dalam pemanfaatan } \\
\text { media }\end{array}$ & & & $\sqrt{ }$ & \\
\hline 10. & $\begin{array}{l}\text { Mengaitkan media dengan realitas } \\
\text { kehidupan }\end{array}$ & & & $\sqrt{ }$ & \\
\hline 11. & $\begin{array}{l}\text { Memberi kesempatan kepada tim untuk } \\
\text { membacakan hasil diskusi }\end{array}$ & & & $\sqrt{ }$ & \\
\hline 12. & Menjelaskan materi secara menyelunuh & & & & $\sqrt{ }$ \\
\hline 13. & Memberi evaluasi & & & $\sqrt{ }$ & \\
\hline & & & & & \\
\hline
\end{tabular}

Skor $=\frac{\text { Skor Total }}{\text { Skor Maksimal }} \times 100$

Keterangan :

$$
\begin{aligned}
& =\frac{45}{52} \times 100 \\
& =86,5
\end{aligned}
$$

$1=$ Tidak Baik

$2=$ Kurang Baik

$3=$ Cukup baik

4 = Baik

\section{Standar Ketuntasan Minimal 65}

(Sumber: Kurikulum 2013) 
Tabel Kegiatan Siswa Siklus II

\begin{tabular}{|c|c|c|c|c|c|}
\hline \multirow[t]{2}{*}{ No. } & \multirow[t]{2}{*}{ Aspek yang diamati } & \multicolumn{4}{|c|}{ Skala Nilai } \\
\hline & & 1 & 2 & 3 & 4 \\
\hline 1. & Siswa memperhatikan penjelasan guru & & & $\sqrt{ }$ & \\
\hline 2. & $\begin{array}{l}\text { Siswa membuat kelompok sesuai dengan } \\
\text { perintah guru }\end{array}$ & & & $\sqrt{ }$ & \\
\hline 3. & Siswa mampu bekerja sama & & & $\sqrt{ }$ & \\
\hline 4. & Siswa ikut serta dalam penggunaan media & & & $\sqrt{ }$ & \\
\hline 5. & $\begin{array}{l}\text { Siswa aktif bertanya dan menyampaikan } \\
\text { pendapat }\end{array}$ & & & $\sqrt{ }$ & \\
\hline 6. & Siswa membuat laporan kegiatan & & & & $\sqrt{ }$ \\
\hline 7. & Siswa mengerjakan tes evaluasi & & & & $\sqrt{ }$ \\
\hline & Total & & & & \\
\hline
\end{tabular}

Skor $=\frac{\text { Skor Total }}{\text { Skor Maksimal }} \times 100$

Keterangan :

$$
\begin{aligned}
& =\frac{23}{28} \times 100 \\
& =82,1
\end{aligned}
$$

$1=$ Tidak Baik

$2=$ Kurang Baik

3 = Cukup baik

$4=$ Baik

\section{Standar Ketuntasan Minimal 65}

(Sumber: Kurikulum 2013)

\begin{tabular}{|c|c|c|c|c|}
\hline \multirow[t]{2}{*}{ No. } & \multirow[t]{2}{*}{ Nama Siswa } & \multirow[t]{2}{*}{ Nilai/Skor } & \multicolumn{2}{|c|}{ Keterangan } \\
\hline & & & Tuntas & Tidak Tuntas \\
\hline 1. & Ahmadi & 80 & $\sqrt{ }$ & \\
\hline 2. & Fera Dwi Yanti & 80 & $\sqrt{ }$ & \\
\hline 3. & Hendy Febriansa & 70 & $\sqrt{ }$ & \\
\hline 4. & Lilis Karlina & 70 & $\sqrt{ }$ & \\
\hline 5. & Rustini & 80 & $\sqrt{ }$ & \\
\hline 6. & Sania Nur Cahya & 80 & $\sqrt{ }$ & \\
\hline 7. & Wedy Ardiansyah & 80 & $\sqrt{ }$ & \\
\hline & Jumlah Skor & 540 & 7 & 0 \\
\hline & Klasikal & & $100 \%$ & $0 \%$ \\
\hline
\end{tabular}

\section{Tabel Hasil Belajar Siswa Siklus II}

Jumlah skor maksimal $=700$
Skor Tercapai/Rata-rata

$=\frac{\text { Jumlah Skor }}{\text { Skor Maksimal }} \times 100$

$=\frac{540}{700} \times 100$

$=77,14$

Ketuntasan Belajar

$=\frac{\text { Siswa Tuntas }}{\Sigma \text { Siswa }} \times 100$

$=\frac{6}{7} \times 100$

$=100 \%$

$=100 \%$ Ketuntasan Klasikal

(Tuntas )

Tabel Distribusi Hasil Belajar Siswa Siklus II

\begin{tabular}{|c|l|c|}
\hline No. & \multicolumn{1}{|c|}{ Aspek yang diamati } & Presentase \\
\hline 1. & Nila rata-rata & 77,14 \\
\hline 2. & Jumlah siswa yang tuntas belajar & 7 \\
\hline 3. & Presentase ketuntasan belajar klasikal & $100 \%$ \\
\hline
\end{tabular}

Pada tahap refleksi ini akan dikaji apa yang telah terlaksana dengan baik maupun yang masih kurang baik dalam proses belajar menggunakan strategi Example Non Example dengan bantuan media gambar, data yang diperoleh dapat diuraikan sebagai berikut:

1). Selama proses belajar mengajar, guru dan siswa telah melaksanakan proses pembelajaran dengan cukup baik dengan hasil 86,5 dan 82,1. Angka tersebut berada di atas angka standar yang ditentukan yaitu 65 .

2). Siswa sudah mulai menunjukkan aktifitas dan daya kreatifitasnya selama proses belajar mengajar. 
3). Perbaikan dari siklus I telah nampak pada siklus II. Aspek yang diamati sebagian besar berubah ke arah yang lebih baik.

4). Hasil belajar siswa sempurna dan mengalamai ketuntasan, dapat dilihat secara klasikal yaitu $100 \%$. Nilai tersebut $15 \%$ di atas angka standar yang ditentukan yaitu $85 \%$.

Pada siklus II penerapan strategi Example Non Example dengan bantuan media gambar sudah lebih baik, dilihat dari aktifitas guru dan siswa serta hasil belajar siswa meningkat pesat, maka tidak diperlukan revisi terlalu banyak, tetapi yang perlu diperhatikan untuk pelaksanaan proses belajar mengajar berikutnya adalah dengan memaksimalkan atau paling tidak mempertahankan pencapaian pada saat ini, dengan tujuan agar pada pelaksanaan proses belajar mengajar selanjutnya dapat memecahkan persoalan-persoalan yang ada, sehingga tujuan pembelajaran dapat tercapai.

Akhirnya, dengan tercapainya ketuntasan sesuai dengan kriteria yang ditetapkan, tercapai pula tujuan yang terbukti dalam hipotesis penelitian, maka penelitian ini dikatakan berhasil. Kesimpulan dari pelaksanaan penelitian ini adalah Penerapan Strategi Example Non Example dengan bantuan media gambar dapat meningkatkan hasil belajar siswa pada mata pelajaran IPA materi Peristiwa Alam untuk siswa kelas V di SD Negeri 4 Patokan,
Kecamatan Situbondo, Kabupaten Situbondo.

\section{KESIMPULAN}

Hasil kegiatan pembelajaran yang telah dilakukan selama dua siklus dan berdasarkan seluruh analisis dan pembahasan yang telah dilakukan, dapat disimpulkan bahwa penerapan strategi Example Non Example dengan bantuan media gambar pada materi peristiwa alam memiliki dampak positif dalam meningkatkan hasil belajar siswa yang ditandai dengan peningkatan ketuntasan belajar siswa dalam setiap siklus, yaitu masing-masing $71,43 \%$ dan $100 \%$. Penerapan strategi Example Non Example dengan bantuan media gambar pada materi peristiwa alam mempunyai pengaruh positif yaitu dapat meningkatkan motivasi belajar siswa yang ditunjukkan oleh nilai rata-rata siswa pada setiap siklus, yaitu masingmasing 71,43 dan 77,14. Penerapan strategi Example Non Example dengan bantuan media gambar pada materi peristiwa alam dapat mengingatkan kembali materi ajar yang telah diterima siswa, sehingga mereka siap untuk menghadapi ujian kenaikan kelas yang akan segera dilaksanakan..

\section{DAFTAR PUSTAKA}

Azmiyawati, Choiril., Wigati Hadi Omegawati., Rohana Kusumawati. 2008. IPA 5 Salingtemas untuk Kelas $V$ SD/MI. Jakarta: Pusat 
Perbukuan Departemen Pendidikan Nasional.

Huda, Miftahul. 2013. Model-model Pengajaran dan Pembelajaran. Yogyakarta: Pustaka Pelajar.

Rusman. 2012. Model-model Pembelajaran.

Jakarta: PT RajaGrafindo Persada.
Sudjana, Nana., Ahmad Rivai. 2010. Media Pengajaran. Bandung: Sinar Baru Algensindo.

Sugiyono. 2012. Metode Penelitian Kuantitatif, Kualitatif, dan $R \& D$. Bandung: Alfabeta. 